\title{
BUILDING COALITIONS: Making A Difference Needs Assessments
}

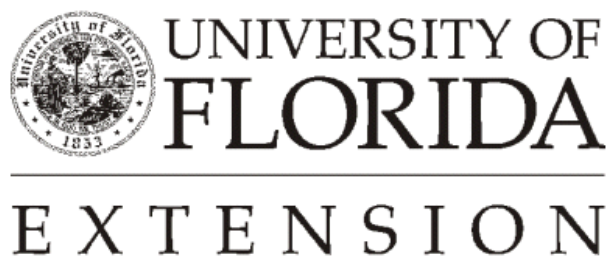

Institute of $\mathbf{F}_{\text {ood and }} \mathbf{A}_{\text {gricultural }} \mathbf{S}_{\text {ciences }}$ 


\section{Needs Assessments for Building Coalitions}

A collaborative effort is necessary to effectively impact the problems that face youth and families today. Ask: Are you making a real difference in the lives of young people and their families? Would it be easier to encourage a positive change if you worked with other community agencies and support groups who have a youth and family focus? Individually, you can't do everything, but collectively, something can be accomplished. By building coalitions in your community, neighborhoods or county, the lives of youth and their families can be positively affected.

\section{Understanding Needs Assessment}

Several questions frequently are asked about needs assessment.

What is meant by needs assessment? Needs assessment is a process for identifying gaps in results and arranging them in priority order for resolution. These gaps are discrepancies between what should be and what are the current conditions. The most important ones are selected for action. In this definition it is important to note that need is used as a noun - a gap or discrepancy. This is different from the traditional definition and use of need as a verb - require or demand.

How can needs assessment be used? Needs assessment can be used in several ways. Sometimes, the gap between "what is" and "what should be" establishes the objectives for programs. For example, in examining the teenage pregnancy rate, classes might be established to help these individuals adjust to their parental roles. Other options might be to present birth control information to young people or encourage them to abstain from sexual activity until after they marry. Any or all these objectives could result from conducting a needs assessment.

Needs assessment also will help select the strategy a program might use. Suppose the basic reading level of at-risk youth was found to be inadequate. One strategy would be to require that young people take more reading courses before they graduate from high school. Another would be to change the way current reading courses are taught in the elementary schools. You might reward at-risk students for the number of books they read from the library. Information about the perceptions students, teachers, parents and employers have of these strategies could help in the selection of an appropriate approach.

Sometimes needs assessment information is used for designing or modifying an instructional program. For example, unsatisfactory academic performance can be attributed to inappropriate teaching styles. Individuals who learn by concrete examples often find it difficult to comprehend ideas presented in an abstract manner. Determining the learning styles of students and comparing it with the teaching style of instructors can provide helpful information in this modification process.

Needs assessments also can be used to evaluate progress. By administering a needs assessment instrument again, it would be possible to check the headway made in reducing a discrepancy or gap. This is similar to the procedures used in administering pre-and post-tests. 
What are the advantages of using needs assessment? Conducting needs assessment provides many advantages to individuals planning collaborative efforts. A major advantage is the generation of new ideas and alternatives for dealing with needs. The saying, "two heads are better than one" is appropriate for individuals who together conduct a needs assessment.

It also provides an opportunity for job enrichment. Individuals can get bored with their jobs or burned-out. Needs assessment offers opportunities to deviate from their routine and revitalize themselves. Contact with other individuals concerned with similar conditions can provide a support group with stimulation and encouragement that is often absent when one is working alone.

When resources are scarce, it can be difficult to develop effective programs. Collaboration in conducting a needs assessment can help identify similar personnel, facilities, equipment and, funds in other organizations and agencies. The pooling of these resources may allow collaborators to offer programs that none could have alone.

Another advantage is the strength there is in numbers. Individuals who choose to work together on important needs often find it easier to generate support for their cause. Collaborators also can benefit from their increased "clout" with potential funders and policy makers.

What problems can arise in a collaborative needs assessment? Needs assessment can have problems for those planning collaborative efforts. Individuals may complain when additional meetings are scheduled. This is especially true for busy people. Potential collaborators need to be shown the benefits of working together in needs assessment. You might even suggest how time could be saved in the long run.

The group also needs to decide who will be responsible for providing effective leadership. Designate one individual to chair the group. If everyone is responsible for leading, it generally turns out that no one is responsible and the effort becomes disjointed.

The channels for communication among group members present yet another challenge. When busy people are involved, much time can be wasted with "telephone ping-pong." The use of facsimile (fax) and answering machines is one way to simplify communication.

In the early states of collaboration, the needed resources are difficult to obtain. When these resources can be identified, a list of the requirements should be shared with the group. This should help the committee see who is contributing what resources and encourage everyone to contribute their fare share.

Establishing a mission and clear objectives for the collaborative needs assessment also can provide obstacles. "Turf battles " sometimes emerge and individual agendas-both hidden and explicit-become problematic. Members of the group should concentrate their efforts on the intended results and minimize the struggles between individuals. 
Individual client groups of the various collaborators can become alienated if they are not brought along as the needs assessment effort develops. Some clients will think their organization is being "short-changed" if the collaborative effort becomes too visible too soon. Although several potential problems have been identified, all or most of the problems in any one situation can be resolved. Members of the collaborative group need to be alert to these types of problems and work to eliminate them before they block the needs assessment effort.

\section{Involving Others}

When it becomes apparent what others are doing to address youth and family issues, you can be better prepared to become involved in community networks, coalitions or collaborative efforts. Look beyond your organization for other agencies or groups who are also involved in the youth and family arena. Possibilities include:

1. Chambers of Commerce

2. Churches

3. Children's Services

4. Community service clubs

5. Extension Service

6. Human Services Department

7. School systems (public and private)

8. United Way

9. YMCA or YWCA

Who should be asked? Coalition members need to be credible and trustworthy. They should be people in the community who share common goals and interest; people who are willing to compromise individual or agency gain for the coalition's aims and objectives.

How do you find these people? Look through the telephone book. Check with your associates and staff members. Explore existing youth and family coalitions in the community. Get invited to service club functions. Attend parent-teacher and school board meetings. Become visible in the community. Be willing to serve on local boards and committees. Write articles for the local newspapers. 
When should they be asked? Do not become discouraged if success does not happen overnight. In building a coalition or getting involved in an existing one takes time. Get to know your community. Become familiar with local power structures. Seek others who have similar goals and are committed to making a difference in the community.

\section{Planning and Designing A Needs Assessment}

There is no agreed upon right way to conduct a needs assessment. (Witkin 1984) The methods for gathering the necessary information are almost unlimited. Be creative, efficient and effective. You may not have to "work harder" if you "work smarter" in gathering what you need. Here are some guidelines to help in planning and designing a needs assessment.

1. Determine the purpose for conducting the needs assessment. Among these purposes are: generating awareness, satisfying a mandate, aiding in decision-making or promoting action.

2. Define the goals and objectives for the needs assessment. Show what it is you want to find out about whom. What type of information do you want-demographic, awareness, attitudinal or behavioral? Who will be the target audience? Decide whether you are concerned about just those clients you currently serve or if you wish to broaden your client base to the total community. Be specific.

3. Select the approach you will take in collecting the information. Decide whether the information you needs exists, if a new data collection effort is needed or if you will need to use a combination of approaches.

Most agencies have some types of available information. For example, your organization might already have important information in a management information system (MIS) or document(s); or, you might have conducted surveys of your clients. Another potential source of information is the U.S. census. Much of that data is already summarized by county and state.

If the type of information you want is not available, then it must be collected. One common method is to gather data by a mailed questionnaire. Valuable information also might be collected by interviews. Observation of conditions and situations is also a potential source. Other useful techniques include the use of focus groups, public hearings or forums.

You may need to combine approaches. A limited amount of the information may be available, but other key data is missing.

4. Design the instrumentation and procedures. When designing them, "keep it simple." Long and complicated instruments discourage response. Additionally, short instruments are less expensive to produce, distribute, collect, and analyze. Once you have prepared a draft of the instrument, check it against the original proposal(s), goals and objectives to make sure nonessential information has not been included. 
Check to see if it needs to be reviewed by a human subjects committee. Many universities and schools require such clearances.

5. Prepare an estimated time line and budget for the needs assessment. These activities will help keep the procedures on target. In addition, cooperating agencies will see how they can make "in-kind" contributions and help make the needs assessment more cost effective.

6. Conduct a pilot test of the instrumentation and procedures. Many mistakes can be identified and eliminated by trying them with a small group.

7. Collect the information. Limit the collection time to no more than six weeks. This will help develop a sense of urgency and keep the needs assessment targeted.

8. Analyze the data and information. If there is a large response, try to have access to a computer to conduct the statistical analyses. There are also software packages to analyze qualitative data.

9. Prepare a report of the findings. Make it as user-friendly as possible. Do not create a long document. It is probably better to divide the report into several brief documents than one long one. Consider using "white space" and figures to help communicate important points. Also, consider developing audio-visual reports. Video-tapes, transparencies and slides can be effective in communicating results.

10. Evaluate your efforts. Take time after the needs assessment has been completed to judge its merit and worth. What worked well? What problems were encountered? How could you have done it better? Once the evaluation is complete, share it with others interested in needs assessments. This will provide an opportunity to learn from one another.

\section{Reporting Information}

Once the data collection portion of the community needs assessment process is complete, you have the components that will make, in essence, a "scouting report." Now you must be able to compress and present that data in a concise format, insuring also that it will be used.

Consider:

- $\quad$ People differ on how they prefer to receive information. Prepare multiple reports using a variety of media.

- $\quad$ People rarely read reports cover to cover. Make the community needs assessment report readable, including an executive summary. Keep a logical sequence in mind, use an outline and language that is easily understandable. Start with the most important information. 
- $\quad$ Do not be afraid to list or identify the limitations and alternative explanations. This should increase the credibility of your processes.

- Include oral reports as well as written documents. Remember an oral report requires the quick engagement of the audience with key points of interest. They allow for interaction, which could serve to generate new ideas and insights.

- $\quad$ Report only that which is important. Make sure the audience knows why the needs assessment was completed, what is now known that was not known before and how the new information will help you get where you are going. Keep information relevant, practical, applicable, credible and understandable.

\section{Using Information}

Three fundamental guidelines increase the likelihood that your community needs assessment results will be used.

1. Issues that users perceive as important must have been addressed.

2. The information must be communicated to the appropriate potential users.

3. The information must be transferred in a timely and understandable form.

Early in the process, identify who might have the most interest in the results. Keep in touch with potential users and cultivate new ones. There is no real end to the process, and the community needs assessment will form the beginning of a coalition to address an issue or issues that will require future assessments.

The primary use of the community needs assessment will be to give form and direction to the coalition in addressing issues that pose threats to opportunities for youth in the community. The primary users of the information will be youth agencies, youth organizations and youth development managers. However, there also will be secondary users of such information, which would include other community organizations and agencies, parents and the public in general.

Once information is shared and the important players are familiar with the results of the assessment, someone must take the leadership to establish a working framework. The first decision will be whether a coalition should be initiated. This will depend not only upon the issues identified, but also upon the availability of resources to address those issues. The option of NOT forming a coalition should be appropriately considered.

Use the information identified through the needs assessment to determine the mission statement of the coalition, build the goals and objectives of the coalition, and outline the coalition's action plan. Use the original information as a benchmark as you proceed through the coalition's action plan, keeping in mind that it may need periodic updating. 


\section{References}

Kaufman, Roger. "Relating Needs Assessment and Needs Analysis." Performance and Instruction (November/December 1989).

. Identifying and Solving Problems: A System Approach. 3d ed. San Diego: University Associates, 1982.

Krueger, Richard A. "Reporting Evaluation Results: 10 Common Myths," Paper presented at the annual meeting of the American Evaluation Association, Kansas City, November I, 1986.

Morris, Lynn Lyons, Carol Taylor Fitz-Gibbon and Marie E. Freeman. How to Communicate Evaluation Findings. Beverly Hills, California: Sage Publications, 1987.

Witkin, Belle Ruth. Assessing Needs in Educational and Social Programs. San Francisco: Jossey-Bass Inc., Publishers, 1984.

\section{Authors}

Thomas M. Archer, Associate Professor, Extension Agent, 4-H, Ohio Cooperative Extension Service, The Ohio State University..

Robert Cripe, Extension Agent, 4-H/CNRD, Ohio Cooperative Extension Service, The Ohio State University.

N.I. McCaslin, Associate Professor, Agricultural Education, The Ohio State University.

(C) 1992 The Ohio State University 
This series on Coalition Building was developed by The Ohio Center For Action on Coalition Development for Family and High Risk Youth, Richard Clark, Ph.D., Director. It has been adapted for County Extension Faculty in Florida to facilitate work with local and regional organizations and groups such as non-profits, cooperatives, county extension associations, and others that might benefit from a plan for working together to achieve support for mutual goals.

This document is FY501, Part 9 of the 16 part series adapted for use in Florida by Elizabeth B. Bolton, Professor, Community Development and Lisa Guion, Assistant Professor, Program Planning and Evaluation; Department of Family, Youth and Community Sciences, Florida Cooperative Extension Service, Institute of Food and Agricultural Sciences, University of Florida, Gainesville, 32611-0310.

Reprinted with permission March, 1997. Revised April, 2002.

The Institute of Food and Agricultural Sciences is an equal opportunity/affirmative action employer authorized to provide research, educational information and other services only to individuals and institutions that function without regard to race, color, sex, age, handicap, or national origin. For information on obtaining other extension publications, contact your county Cooperative Extension Service office.

Florida Cooperative Extension Service/Institute of Food and Agricultural Sciences/University of Florida/Christine Taylor Waddill, Dean 